\title{
MODIFIKASI KEMUDI MANUAL MENJADI TIPE RACK AND PINION PADA ANGKUTAN PEDESAAN
}

\author{
Erik Heriana *), Wegie Ruslan **), Asrul Ismail ***) \\ Program Studi Magister Teknik Mesin, Universitas Pancasila, Jakarta
}

\begin{abstract}
ABSTRAK
Sarana dan prasarana yang baik sangat erat kaitannya dengan hasil sebuah pekerjaan, hal inilah yang mendorong untuk menciptakan sebuah alat transportasi desa yang dapat menunjang kegiatan dan mobilitas civitas akademika yang tinggi, sehingga akan menghasilkan hasil yang maksimal.. Sebagai wujud kepedulian terhadap masalah di pedesaan, maka penulis bermaksud untuk mengkaji sebuah konsep kendaraan angkutan pedesaan roda empat dengan kapasitas berpenumpang lima orang dan barang $500 \mathrm{~kg}$ lebih yang sekaligus menjadi tonggak perubahan angkutan pedesaan di Indonesia.
\end{abstract}

Metodologi yang digunakan penulis adalah dengan metoda kajian perhitungan desain ulang untuk proses modifikasi sistem kemudi pada kendaraan angkutan pedesaan roda empat yang nyaman dan aman. Perhitungan diawali dengan mengkaji sudut belok kendaraan, kemudian mengkaji steering geometri dan beban yang diterima kemudi.

Dari hasil kajian ini dapat disimpulkan bahwa kendaraan angkutan pedsaan roda empat yang di desain mempunyai Sistem streering kendaraan ini menggunakan Rack and Pinion dengan sudut roda bagian luar dan bagian dalam masing - masing adalah dan. Pergeseran rack sebesar 7,47 cm mengakibatkan rasio steering 13, rasio steering ini adalah perbandingan dari hasil pergeseran rack dalam satu putaran dibagi dengan luas roda. Beban pada system steering sebesar 3,14 N ini dianggap ringan sehingga kendaraan ini tidak perlu menggunakan power steering, karena beban masih dalam standar yang dipersyaratkan yaitu 2 sampai dengan $7 N$.

Kata kunci : Sistem, kemudi ringan, nyaman dan aman.

\begin{abstract}
Good facilities and infrastructure that is closely associated with the results of a job, it is the driving force to create a transportation country to operate, easy to maintain, that can support the activities and the high mobility of the academic community, so it will produce results maximum .. As we care about the problem of the country in the country of Indonesia, the author intends to examine a four-wheeled rural transport vehicle concept with a passenger capacity of five people and carry to $500 \mathrm{~kg}$ who also became a milestone towards Indonesia rural transport vehicles.
\end{abstract}

The methodology used by the author is the calculation method of the study design steering system on fourwheeled rural transport vehicles comfortable and safe. The calculation begins by reviewing the turn angle of the vehicle, and then examines the steering geometry and load received steering.

From the results of this study it can be concluded that the four-wheel electric vehicles in the design of these vehicles have streering System Rack And Pinion using the outer wheel angle and the inside of each - each is and. Shift of $7.47 \mathrm{~cm}$ resulted rack steering ratio 13 steering ratio is a comparison of the results in a single rack shift divided by the area round the wheel. The load on the steering system 3,14 $\mathrm{N}$ is considered to be mild so that these vehicles do not need to use power steering, because the burden is still within the required standard is 2 to $7 \mathrm{~N}$.

Keywords: system, steering comfortable and safety factor. 


\section{PENDAHULUAN}

Berkembangnya dunia otomotif, khususnya mobil tentunya sangat sesuai dengan tingkat kebutuhan manusia itu sendiri akan kendaraan, dimana setiap pemunculan produk mobil baru sudah barang tentu menawarkan perkembangan teknologi yang memberikan kemudahan dan kenyamanan serta keamanan yang lebih baik bagi pengendara maupun penumpang mobil.

Salah satu jenis angkutan pedesaaan mobil kolot/tua er tahun ' 92 ke bawah yang masih banyak digunakan pedesaan adalah Carry Futura, T.120.SS, Daihatsu Zebra yang merupakan produksi dari Industri yang berada di kita.Kendaraan tersebut masih di pergunakan di daerah Cikalong -Padalarang Kabupaten Bandung Barat dan Cisarua Kota Cimahi (yang terkenal banyak belokan /manuver tajam dan tanjakan).

Kelemahan yang sangat dirasakan oleh para pemilik kendaraan ini adalah bahwa jarak radius putar mobil ini bisa dikatakan kurang baik, selain itu untuk membelokkan mobil ini diperlukan tenaga ekstra. Dalam pengendalianpun bisa dikatakan kurang responsive dan handling dari mobilpun dirasakan kurang baik.

Jenis Angkutan pedesaan yang tua sendiri untuk Steering system-nya adalah Steer House yang menggunakan Worm Gear (roda gigi cacing), dimana secara teoritis elemen mesin sendiri merupakan jenis roda gigi yang dalam hal mentransmisikan daya memiliki efisiensi yang rendah. Kemudian dari sisi Linkage system ini pun ternyata memberikan hasil dimana handling kurang baik dan kurang responsive.

Berdasarkan pendahuluan diatas perlu diadakan indentifikasi masalah yang dipengaruhi, struktur bodi, kendaraan yang hemat energi, arodinamis dan berat dapat lihat pada saat berbelok atau manuver. Dengan tujuan :

1. Menghasilkan gaya hambat (drag) aerodinamik, gaya angkat (lift) aerodinamik, gaya samping (side) aerodinamik, dan hambatan ketika kendaraan berjalan.
2. Menghasilkan desain perubahan sistem kemudi yang baik di mobil angkutan pedesaan tua dan berdampak pada kenyamanan dalam berkendara.

3. Menghasilkan desain yang aerodinamik dan mempercepat aliran udara pada bagian bawah, sehingga kecepatannya lebih baik.

4. Menekan biaya teknologi kendaraan dalammobl tua karena desain kendaraan yang lebih ringan namun memenuhi persyaratan keamanan.

\section{METODE PENELITIAN}

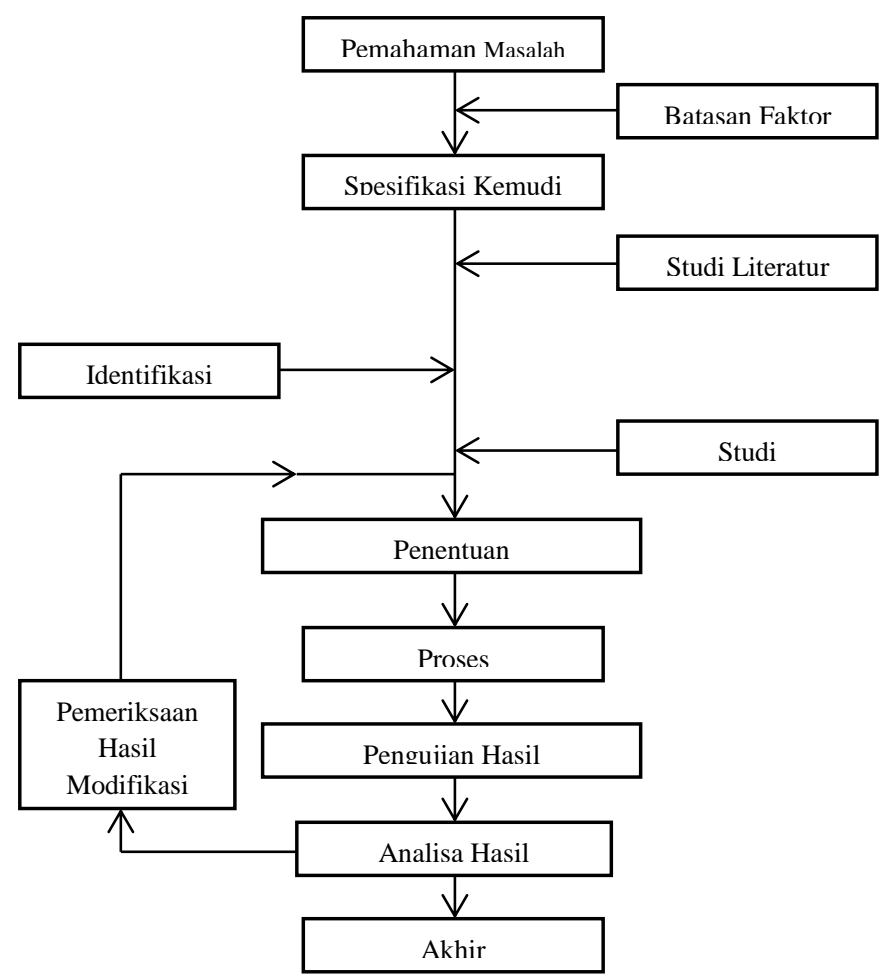

\section{Gambar 1.1 Skema Metode Perancangan Ulang Modifikasi}

Tujuan penelitian adalah pertimbangan dalam mengemudi angkutan pedesaan kolot/tua dan berat saat manuver/ berbelok menjadi penyebab untuk meningkatnya kenyamanan dan keamanan oleh supir angkutan tua, kelemahan dari mobil memiliki angkutan pedesaan kolot/tua dan berat saat manuver/ berbelok dan perbaikan sistem kemudi, maka dimodifikasilah sistem kemudi kendaraan yang optimal sehingga memenuhi stabilitas kendaraan dan model yang menarik serta lebih ringan sehingga dapat mengatasi 
masalah kenyaman dan keamanan pengemudi angkutan tua

Pengumpulan data-data yang dibutuhkan, dilakukan dengan mengambil hasil perancangan ulang / pemodifikasian dan data dari mobil ELDIS 1.3 (Angkutan Pedesaan Tua tahun 1991) itu sendiri. Datadata angkutan pedesaaan tersebut, yaitu:

○ Data Kendaraan:

- Berat Kendaraan : 1420 $\mathrm{Kg}$

- Berat pada roda depan : $490 \mathrm{Kg}$

- Wheel Base : 1960 $\mathrm{mm}$

- Pivot Center : 1560 $\mathrm{mm}$

- Jarak Tie Rod Center : : 44,1 inch

- Jarak Tie Rod ke Ball Joint: 4,3 inch $=110 \mathrm{~cm}$

- Front Wheel Track : 1140 $\mathrm{mm}$

- $\quad$ Rear Wheel Track $\quad$ : 1380 $\mathrm{mm}$

- $1 / 2$ Ackermann Angle $(\alpha)$ sebesar : $27,88^{0}$

$$
\begin{aligned}
& \text { X } \\
& =l \cdot \cos \left[\frac{\arcsin \left(l \cdot \sin \beta-\left\{s \cdot \sqrt{2-2 \cdot \cos \delta_{1} \cdot \cos \left(90-\alpha-\frac{\delta_{1}}{2}\right)}\right\}\right)}{l}\right] \\
& +s \cdot \sqrt{2-2 \cdot \cos . \delta_{1}} \cdot \sin \left(90-\alpha-\frac{\delta_{1}}{2}\right)-l \cdot \cos \beta
\end{aligned}
$$

Untuk perubahan sudut roda bagian luarnya didapat pula persamaan, yaitu:

$$
\begin{aligned}
& \text { l. } \sin \left[\arctan \left(\frac{l \cdot \sin \beta}{l \cdot \cos \beta-X}\right)\right] \\
& =\text { l. } \sin \beta \\
& + \text { s. } \sqrt{2-2 \cdot \cos \delta_{o}} \cdot \cos \left(90-\alpha-\frac{\delta_{o}}{2}\right)
\end{aligned}
$$

Keterangan:

$$
\begin{array}{lll}
\circ & l \quad: \text { Panjang Rack End } \\
\circ & s \quad \text { : Steer Arm (Jarak Pivot center } \\
& \text { dengan Tie Rod) } \\
\circ & \alpha: 1 / 2 \text { Ackermann angle } \\
\circ & \beta \quad: \text { Sudut antara perpanjangan Rack } \\
\text { dan Rack End }
\end{array}
$$

Kedua persamaan diatas merupakan persamaaan yang untuk Rack \& Pinion steering system akan selalu digunakan. Tentunya faktor yang akan membedakan untuk setiap mobil adalah Wheel Base (jarak center roda depan dengan center roda belakang) dan pivot center (jarak antara kedua pivot atau balljoint sebagai pusat perputaran).

Untuk Angkutan Pedesaaan memiliki data sebagai berikut :

- Berat kendaraan : 1520

$\mathrm{Kg}$

- Berat pada roda depan $\quad: 490 \mathrm{Kg}$

- Whell Base : $1960 \mathrm{~mm}$

- Pivot Center $: 46,1$ inch $=1170$ $\mathrm{cm}$

Pada Rack \& Pinion steering system, steering geometry yang didapat adalah hasil dari analisa kinematis yang dilakukan pada linkage systemnya (berupa desain akhir dari Rack \& Pinion Steering System).

○ Pergeseran Rack

- Jarak Tie Rod Center : 44,1 inch

- Jarak Tie Rod ke Ball Joint: 4,3 inch = $110 \mathrm{~cm}$

- Front Wheel Track : $1440 \mathrm{~mm}$

- Rear Wheel Track : $1380 \mathrm{~mm}$ 
- $1 / 2$ Ackermann

Angle $(\alpha)$ sebesar $: 27,88^{\circ}$

Dari manual Service Book untuk angkutan Angkutan Pedesaan tahun 1991 didapat bahwa Inner Wheel Angle $\left(\delta_{1}\right)$ maksimum adalah $34^{\circ}$ dan Outer Wheel Angle $\left(\delta_{0}\right)$ maksimumnya adalah $28^{\circ}$, sedangkan jika menurut teorema Ackermann untuk $\delta_{1}=34^{\circ}$ maka $\delta_{0}=26,02^{\circ}$, hal inilah yang biasanya dikatakan error curve dalam steering geometry. Pada dasarnya error curve ini masih ditolelir sejauh tidak terlalu ekstrim perbandingannya terhadap teorema Ackermann dan inilah yang harus kita eliminir dan dengan Rack \& Pinion Steering System penulis berharap dapat mengeliminir error curve ini.

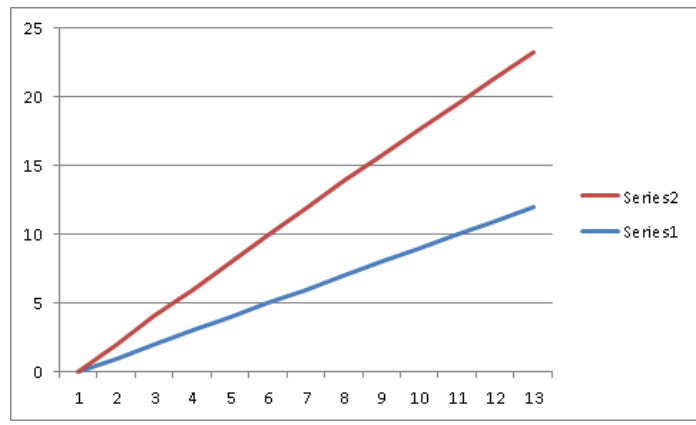

Grafik 1.2 Perbandingan Inner dan Outer Wheel Angle dengan penggunaan Rack \& Pinion Steering System

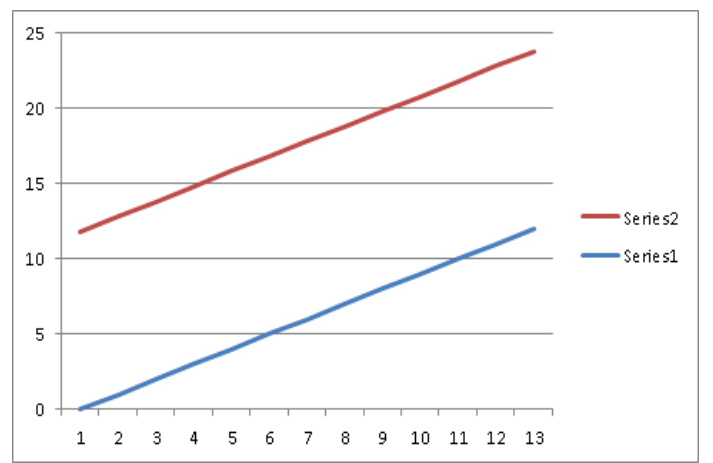

Grafik 1.3 Beban pada Steering Wheel untuk Rack \& Pinion Steering System

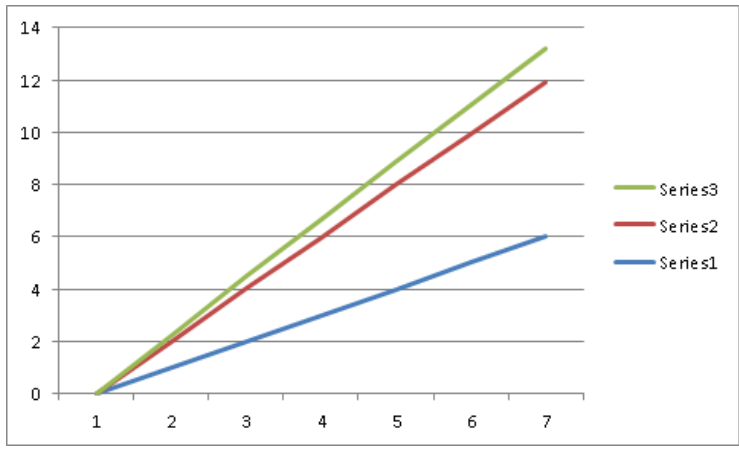

Grafik 1.4 Perbandingan Inner dan Outer Wheel

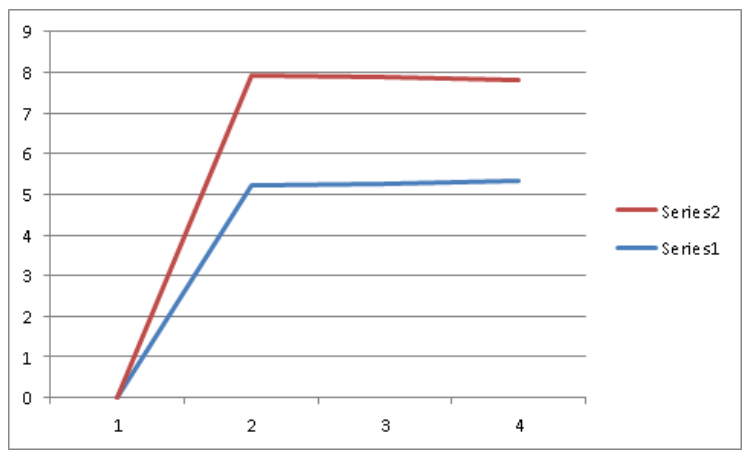

\section{Grafik 1.5 Perubahan Kecepatan dan Percepatan pada Pergerakan Rack}

\section{Perhitungan dan Analisis Sistem Kemudi Sudut Belok Kendaraan}

Sudut belok dihitung untuk mencari radius belok roda depan kendaraan roda empat maka dari analisa gambar dapat dihitung dengan rumus berikut:

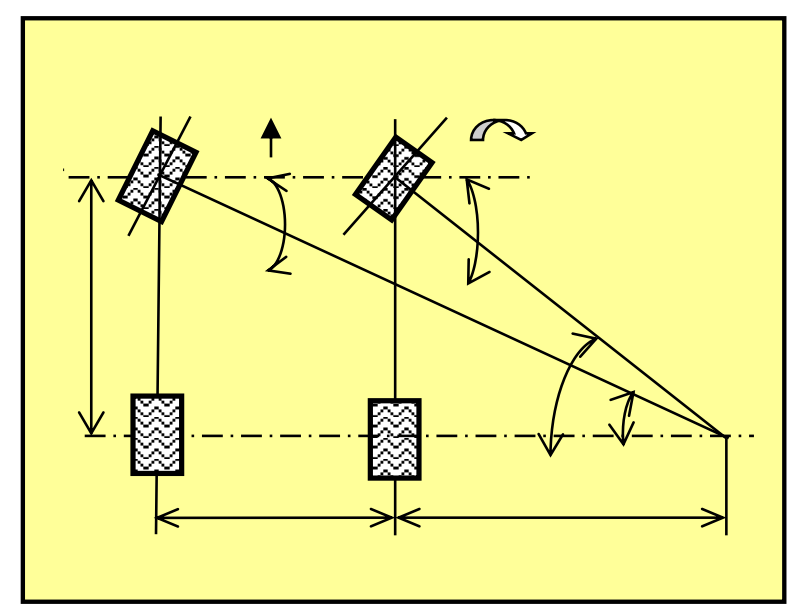

Gambar 1.6. “ Sudut Belok “ 
dari spesifikasi kendaraan yang ada bahwa :

Wheel Base $(\mathrm{L})=2450 \mathrm{~mm}$

Wheel Track $(\mathrm{T})=1560 \mathrm{~mm}$

Dan Radius Putar $(\mathrm{R})=7020 \mathrm{~mm}$

Maka

$$
\begin{gathered}
\delta_{0}=\operatorname{Tg}^{-1} \frac{L}{\left(R+\frac{T}{2}\right)} \\
\delta_{0}=T g^{-1} \frac{2450}{\left(7020+\frac{1560}{2}\right)} \\
\delta_{0}=T g^{-1} 0,31 \\
\delta_{0}=17,44^{0}
\end{gathered}
$$

sehingga sudut belok roda sisi luar (outer) adalah

$$
\begin{gathered}
\delta_{i}=\operatorname{Tg}^{-1} \frac{L}{\left(R-\frac{T}{2}\right)} \\
\delta_{i}=T g^{-1} \frac{2450}{\left(7020-\frac{1560}{2}\right)} \\
\delta_{i}=T g^{-1} 0,39 \\
\delta_{i}=21,43^{0}
\end{gathered}
$$

\subsubsection{Prilaku Ackerman}

Mekanisme steering Tipe Ackerman. Secara skematis komponen utama yang digunakan pada mekanisme steering type ini dapat dilihat pada Gambar

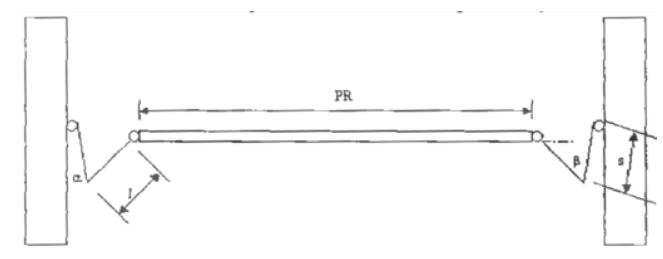

Gambar 1.7 “ Bagan Rack \& Pinion Steering Geometry “.

\section{Keterangan:}

$$
\begin{aligned}
& P R \quad \text { : Panjang Rack }(62,5 \mathrm{~cm}) \\
& l \quad: \text { Panjang Rack End }(27,9 \mathrm{~cm}) \\
& s \quad \text { : Jarak antara Ball Joint (Pivot } \\
& \text { Center) dengan Tie Rod (11,45cm) } \\
& \alpha \quad \text { : Sudut Ackermann }\left(29,04^{\circ}\right) \\
& \beta \quad \text { : Sudut antara Rack dengan Rack }
\end{aligned}
$$$$
\text { End }\left(30,82^{0}\right)
$$

Sedangkan dari kedua persamaan utama untuk Rack \& Pinion steering system diatas maka diperoleh hasil perhitungan sebagai berikut:

$$
\begin{aligned}
& \text { Pergeseran Rack } \\
& =l \cdot \cos \left[\frac{\arcsin \left(l \cdot \sin \beta-\left\{s \cdot \sqrt{2-2 \cdot \cos \delta_{1} \cdot \cos \left(90-\alpha-\frac{\delta_{1}}{2}\right)}\right\}\right)}{l}\right] \\
& + \text { s. } \sqrt{2-2 \cdot \cos \cdot \delta_{1}} \cdot \sin \left(90-\alpha-\frac{\delta_{1}}{2}\right)-l \cdot \cos \beta
\end{aligned}
$$

$$
\begin{aligned}
& X= \\
& 27,9 \cdot \cos \left[\frac{\arcsin \left(27,9 \cdot \sin 30,28-\left\{11,45 \cdot \sqrt{2-2 \cdot \cos 21,43 \cdot \cos \left(90-29,04-\frac{21,43}{2}\right)}\right)\right.}{27,9}\right] \\
& +11,45 \cdot \sqrt{2-2 \cdot \cos \cdot 21,43} \cdot \sin (90-29,04 \\
& \left.-\frac{21,43}{2}\right)-27,9 \cdot \cos 30,28 \\
& X=7,47 \mathrm{~cm}
\end{aligned}
$$

\section{Steering Ratio}

Merupakan perbandingan antara besarnya perubahan sudut pada Steering Wheel dengan perbandingan sudut Steering Wheel dengan sudut pada roda.

$$
\begin{aligned}
& \delta_{x}=\frac{X \cdot 360}{2 \cdot \pi \cdot r} \\
& \delta_{x}=\frac{7,47 \cdot 360}{2 \cdot \pi \cdot 33,02} \\
& \delta_{x}=\frac{7,47 \cdot 360}{2 \cdot \pi \cdot 33,02} \\
& \delta_{x}=13
\end{aligned}
$$

\section{Beban Pada Steering Wheel}

Seperti yang telah disebutkan pada Bab II Tesis ini beban pada steering wheel merupakan faktor yang penting bagi produsen mobil maupun pengendaranya. Seharusnya semua faktor yang akhirnya mempengaruhi beban pada steering wheel benar-benar diperhitungkan.

Asumsi untuk Aligning Torque ( $M_{2}$ ) ditetapkan penulis sebesar $6 \mathrm{Kg} \cdot \mathrm{m}$ dan 
kerugian torsi gaya yang terjadi dikalikan dengan faktor pengali 1.1.

Untuk Rack \& Pinion steering system beban pada steering wheel dapat dihitung sebagai berikut:

- Gaya yang timbul pada Rack akibat Aligning Torque:

$$
\begin{gathered}
F_{R}=2 \cdot M_{2} \cdot \frac{\cos \beta}{s \cdot \cos (90-\alpha-\beta)} \\
F_{R}=2.6 \frac{\cos 30,82}{11,45 \cdot \cos (90-29,04-30,82)} \\
F_{R}=2.6 \frac{0,85}{11,45 \cdot \cos (30,14)} \\
F_{R}=2.6 \frac{0,85}{9,90} \\
F_{R}=1,03 \mathrm{~N}
\end{gathered}
$$

- Gaya yang timbul akibat percepatan pergeseran Rack:

$$
F_{r}=m \cdot a
$$

Keterangan :

$m$ : Massa untuk batang Roda Gigi Rack (asumsi $2 \mathrm{Kg}$ )

$a$ : Percepatan pada saat pergeseran $\operatorname{Rack}\left(0,7 \mathrm{~cm} / \mathrm{s}^{2}\right)$

$$
\begin{gathered}
F_{r}=m \cdot a \\
F_{r}=2 \cdot 0,7 \\
F_{r}=1,4 \mathrm{~N}
\end{gathered}
$$

- Sedangkan akibat kerugian lainnya diasumsikan sebesar 9,81 N

Dengan demikian persamaan untuk beban pada steering wheel adalah :

$W_{3}=\frac{F_{R} \cdot 9,81+F_{r}+9,81}{9,81} \cdot \cos \varphi \cdot \frac{d_{1}}{d_{2}}$

Keterangan :

$\varphi$ : Sudut Intersecting Shaft roda gigi $\left(45,5^{0}\right)$

$d_{1}$ : Diameter Pitch Circle Pinion (13,5 $\mathrm{mm})$

$d_{2}$ : Diameter Steering Wheel (14 inch)

$$
\begin{gathered}
W_{3} \\
=\frac{1,03 \cdot 9,81+1,4+9,81}{9,81} \cdot \cos 45,5 \cdot \frac{13,5}{355,6} \\
W_{3}=\frac{1,03 \cdot 9,81+11,21}{9,81} \cdot 0,99 \\
W_{3}=\frac{19,91+11,21}{9,81} \cdot 0,99 \\
W_{3}=\frac{31,12}{9,81} \cdot 0,99 \\
W_{3}=\frac{30,80}{9,81} \\
W_{3}=3,14 \mathrm{~N}
\end{gathered}
$$

\subsection{Beban yang diterima Roda}

Berat yang ditanggung oleh Suspensi dan Roda bagian depan (wf) :
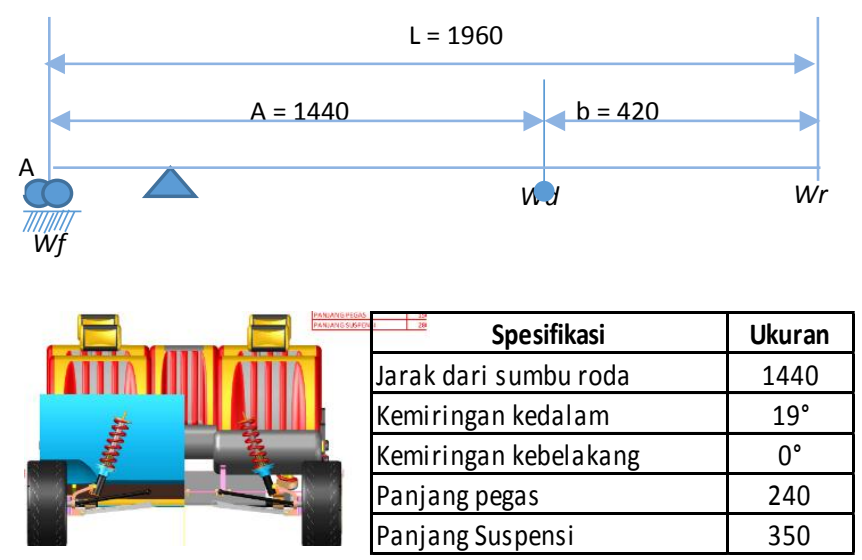

Gambar 1.8. “ Kondisi Pembebanan yang diterima oleh Shock Absorber ".

$$
\begin{array}{r}
w_{f 1}=F_{t} \operatorname{Sin} 71^{0} \\
F_{t}=\frac{w_{f 1}}{\operatorname{Sin} 71^{0}} \\
=\frac{3520}{0,95}
\end{array}
$$$$
=3705,3 \mathrm{~N}
$$

Massa yang ditanggung oleh masing masing roda depan adalah :

$$
=377,7 \mathrm{~kg}=\frac{3705,3}{9,81} m_{f 1}=\frac{F_{t}}{q}
$$

Momen pada titik B :

$$
\begin{gathered}
\sum M_{b}=0 \\
W_{f} \cdot L-W_{d} \cdot b=0 \\
W_{f}=\frac{b}{L} x W_{d}
\end{gathered}
$$




$$
\begin{gathered}
W_{f}=\frac{1440}{1960} \times 15107,4 \\
W_{f}=0,7 \times 15107,4 \\
W_{f}=11099.02 \mathrm{~N}
\end{gathered}
$$

Berat yang ditanggung oleh masing masing roda depan $\left(W_{f 1}\right)$ adalah

$$
\begin{gathered}
=5549,01 N=\frac{11099,01}{2} W_{f 1} \\
=\frac{W_{f}}{2}
\end{gathered}
$$

\section{Analisis Perhitungan}

Dari hasil perhitungan untuk sudut belok bahwa menunjukan sudut roda bagian terluar lebih besar daripada sudut roda bagian dalam yaitu $\delta_{i}=21,43^{\circ}$ dan

$\delta_{0}=17,44^{0}$. Desain system kemudi pada kendaraan ini merupakan perilaku belok kendaraan yang ideal, kendaraan akan berbelok mengikuti gerakan ackerman dimana tidak terjadi sudut slip pada setiap roda.

Pergeseran rack terjadi sejauh $7,47 \mathrm{~cm}$ mengakibatkan rasio steering nya adalah 13 . Standar untuk rasio steering adalah $13-16$, menunjukan bahwa desain system kemudi ini masih dalam standar yang dipersyaratkan kenyamanan. Beban pada steering wheel adalah $W_{3}=3,14 N$ ini menunjukan bahwa system streering ini tidak perlu menggunakan power steering dikarenakan beban cukup ringan untuk memutarkan roda, dimana standar beban steering wheel antara $2-7 \mathrm{~N}$.

\section{KESIMPULAN}

Dari hasil perhitungan dapat disimpulkan bahwa desain system steering pada kendaraan angkutan pedesaan roda dan 5 penumpang untuk di desa sebagai berikut :

1. Sistem streering kendaraan ini menggunakan Rack And Pinion dengan sudut roda bagian luar dan bagian dalam masing - masing adalah $\delta_{i}=21,43^{0}$ dan $\delta_{0}=17,44^{\circ}$.

2. Pergeseran rack sebesar $7,47 \mathrm{~cm}$ mengakibatkan rasio steering 13 , rasio steering ini adalah perbandingan dari hasil pergeseran rack dalam satu putaran dibagi dengan luas roda.

3. Beban pada system steering sebesar 3,14 $\mathrm{N}$ ini dianggap ringan sehingga kendaraan ini tidak perlu menggunakan power steering, karena beban masih dalam standar yang dipersyaratkan yaitu 2 sampai dengan $7 \mathrm{~N}$.

\section{DAFTAR PUSTAKA}

1. Khurmi,R.S.,Gupta,J.K.,ATextBookofM achineDesign,Eurasia

Publishnig House ( Pvt ) Ltd, RamNagar, New Delhi, 1982.

2. AThomas D, Gillispie, Fundamentals of Vehicle Dynamic, Society ofOtomotif Engineers Inc, Warrendale, 1994.

3. ASularso. MSME. Ir, KiyokatsuSuga. 1997. Dasar PerencanaandanPemilihan Elemen Mesin. PT. Pradnya Paramita: Jakarta.

4. Teknologi Otomotif, Prof Ir I Nyoman Sutantra, M.Sc, Ph.D.

5. ISO 2631-1:1985Evaluation of human Exposure to Whole-body vibration Part 1 : General Requirement.Direvisi dengan Iso 2631-1-1997.

6. Erasmus Darwin's Improved Design for Steering Carriages by Desmond KingHele, 2002, The Royal Society, London. Accessed April 2008.

7. Toyota Astra Motor, 1994, Training Manual Steering System Step 2, Jakarta, PT.Toyota Astra Motor.

8. Toyota Astra Motor, 1994, Training Manual Wheel Alignment \& Tires Step 2, Jakarta, PT.Toyota Astra Motor.

9. Astra International Training Center, Basic Mechanic Training 3, Astra Internasional.

10. Toyota Service Training, 1996, New Step 1, Jakarta, PT.Toyota Astra Motor.

11. "Advantages Of Active Steering For Vehicle Dynamics Control" Professor J Ackermann, Dr T B • Unte, And D Odenthal, German Aerospace Center, D 